\title{
Intramuscular salbutamol in treatment of acute exacerbations of childhood asthma
}

\author{
PATRICIA THOMPSON AND MAX FRIEDMAN
}

From the Department of Paediatrics, Whittington Hospital, London

SUMMARY Salbutamol was given by the intramuscular route to children aged 3 to 16 years with an attack of asthma. Results with a dose of $8 \mu \mathrm{g} / \mathrm{kg}$ were favourable but suggested that a higher dose might be more so. 16 children thereafter were treated with $20 \mu \mathrm{g} / \mathrm{kg}$ which produced a greater mean increase in peak expiratory flow rates (PEFR) without increase in side effects. This dose was then used in a double-blind crossover trial of salbutamol against a saline placebo. Half of 36 children treated with $20 \mu \mathrm{g} / \mathrm{kg}$ showed rapid clinical improvement, the maximum rise in PEFR occurring within the first 5 minutes. A rise in pulse rate and occasionally a tremor were the only side effects noted. We conclude that intramuscular salbutamol $20 \mu \mathrm{g} / \mathrm{kg}$ is a safe and useful initial medication in the management of the asthmatic child suffering an acute exacerbation.

Salbutamol, a specific $\beta_{2}$-adrenergic agonist structurally related to isoprenaline, is a proven effective oral or inhaled medication in asthma (Riding et al., 1970). The use of the drug given parenterally has recently received attention and Fitchett et al. (1975) reported the results of the treatment of 11 adults in status asthmaticus with intravenous salbutamol. We considered that the drug might be effective and safe given intramuscularly to children with severe bronchospasm, obviate the necessity for the rapid placement of an intravenous infusion line in a fractious ill child, and make it a possible method of treatment of the child at home by the general practioner. The latter very rarely has access to specialized apparatus required for nebulization of solutions containing bronchodilators, and the intramuscular route may also be preferable in hospitals where the application of a face mask to inhale nebulized bronchodilators may produce unnecessary apprehension in the child. We started with a dose of salbutamol of $8 \mu \mathrm{g} / \mathrm{kg}$ and then proceeded to a dose of $20 \mu \mathrm{g} / \mathrm{kg}$. The final part of our trial consisted of a double-blind crossover study of salbutamol at the higher dosage against a placebo.

\section{Methods}

A series of children admitted to the paediatric wards between September 1974 and September 1975 aged between 3 and 16 years and suffering from acute

Received 14 October 1976 exacerbations of asthma, were entered into the trial, the purpose of which was explained to accompanying parents. Selection of children was based principally on availability of staff and only one child was excluded from the trial during this period as being too ill to participate.

On admission, the height and weight, pulse, blood pressure, respiratory rate, temperature, and peak expiratory flow rate(PEFR; measured on a pneumotachograph) were recorded. Baseline observations of pulse, respiratory rate, and PEFR were made at 5minute intervals for at least 10 minutes. The first 5 children studied were then given $8 \mu \mathrm{g} / \mathrm{kg}$ salbutamol (group 1); the next 16 children $20 \mu \mathrm{g} / \mathrm{kg}$ salbutamol (group 2), and the final 20 children either salbutamol $(20 \mu \mathrm{g} / \mathrm{kg}$ ) or placebo (saline) (group 3).

Pulse, respiratory rate, and PEFR were again recorded at 5-minute intervals for 30 minutes and then at 15-minute intervals for a further $2 \frac{1}{2}$ hours. Continuous ECG monitoring of heart rate and rhythm was carried out on 6 children during treatment but in all others the pulse was taken at the wrist. Blood pressure was taken at 10 and 30 minutes after all injections. Blood gas analysis was done only when clinically warranted as it was felt unjustifiable to subject children to this procedure otherwise, blood being taken by arterial stab during the baseline period and between 10 and 30 minutes after salbutamol administration. The clinical state was observed throughout the trial period and a record made of cyanosis, the use of accessory muscles of respiration, auscultatory findings in the chest, and 
when possible, subjective feelings of dyspnoea and distress.

The 20 children in group 3 were given salbutamol or placebo injection under double-blind conditions in a previously randomized order. A second injection containing the alternative treatment was given 30 minutes later if necessary. All patients were observed for untoward reaction to any medication given during the trial period and for any deterioration in clinical state. No child had to be withdrawn from the trial for the latter reason, but some children received alternative therapy within 30 minutes of starting the trial when they had failed to show improvement.

\section{Results}

A total of 41 children participated in the study and only 5 of these were unable to co-operate sufficiently for reliable recordings of PEFR to be made. Of the remainder only 2 registered a PEFR on admission $<50 \%$ predicted value for that child's height. Mean admission PEFR for the whole group was $27 \%$ of predicted.

Five children were treated with salbutamol $8 \mu \mathrm{g} / \mathrm{kg}$ (group 1) and in 4 of these PEFR was recorded. Of the 5, 2 showed good improvement in clinical state, 2 mild improvement, and 1 did not respond. The mean maximum rise in PEFR for the group was $14 \cdot 2 \pm 3 \cdot 7 \%$ expressed here and subsequently as $\%$ predicted PEFR \pm standard error.

Sixteen children were treated in group 2 with open salbutamol $20 \mu \mathrm{g} / \mathrm{kg}$. 3 were too young for reliable recordings of PEFR to be made; the mean maximum rise in PEFR for the remaining 13 children after treatment was $35 \cdot 4 \pm 6 \cdot 8 \%$. On clinical assessment, 9 of the 16 responded rapidly to salbutamol, so that the attack was felt to have been terminated. No child required further therapy except maintenance oral bronchodilators beginning one hour after the start of the trial, and 3 were discharged home within 4 hours of admission. Of the remaining 7 children, 4 improved slightly after the salbutamol and were treated with aminophylline suppositories (administered 30 minutes after the salbutamol) and oral bronchodilators, plus in one case ACTH. The remaining 3 children did not respond at all and were treated within 30 minutes of receiving the injection with intravenous hydrocortisone and aminophylline.

Twenty children were entered into the doubleblind trial (group 3); 10 received salbutamol as the first injection and 10 placebo. The children who were given placebo first were all given the second injection (salbutamol) but only 4 who were given salbutamol first required a placebo injection. Only 1 child was unable to co-operate in the recording of
PEFR and this child came from the group who received salbutamol first and improved so much that the second injection was not given. The mean maximum rise in PEFR after salbutamol given as the first injection was $36.7 \pm 6.9 \%$ ( 9 patients) and after placebo as the first injection $5 \cdot 8 \%$ (10 patients) $(P=$ $0.005)$. The mean rise in PEFR after salbutamol as the second injection was $54.5 \%$ (10 patients), but as only 4 patients were given the second placebo injection, no test of the significance of this data was done. The change in PEFR recorded by the individual children in this group of patients is set out in the Table.

Ten of these 20 patients showed a marked clinical response to salbutamol after either the first or second injection and needed no further medication except maintenance oral bronchodilators. 7 children improved moderately; 2 of whom were treated only with oral bronchodilators thereafter, 3 received aminophylline suppositories, and 2 were given further salbutamol $20 \mu \mathrm{g} / \mathrm{kg} 60$ minutes after starting the trial. The remaining 3 children required intravenous administration of aminophylline and hydrocortisone. An example of the response of one child treated in the double-blind study is given (Fig. 1).

Of the 36 children treated with salbutamol $20 \mu \mathrm{g} / \mathrm{kg}$ (either open or blind) in whom PEFRs were recorded 24 experienced a rise in PEFR of more than $20 \%$. The maximum increase in PEFR occurred within 5 minutes of the injection in all but 2 cases and in these it occurred 5 to 10 minutes after the injection.

Blood gas analysis was carried out in 8 children. One child received salbutamol $8 \mu \mathrm{g} / \mathrm{kg}, 22$ received salbutamol $20 \mu \mathrm{g} / \mathrm{kg}$ in the open evaluation, and 5 were children taking part in the double-blind trial. No significant fall in $\mathrm{PO}_{2}$ occurred in any child but 4 showed a satisfactory rise. Oxygen was not administered to any of these children. Little change in $\mathrm{PCO}_{2}$ or acid-base balance occurred.

The rise in PEFR did not appear to be related to the state of each child on admission as assessed on their admission PEFR (Fig. 3). Neither did the response to treatment appear to be related to the prior medication received by each child. Many of these children were drawn from regular attenders at the asthma clinic and a larger proportion (23 of the 36 who were treated with salbutamol $20 \mu \mathrm{g} / \mathrm{kg}$ ) had been given oral $\beta_{2}$-receptor stimulants within 4 hours of admission. The mean rise in PEFR for the group previously treated thus was $34 \pm 7 \%$, and that of the group not so treated $38 \pm 15 \%$, a nonsignificant difference. 13 of these 36 children were on regular therapy with inhaled steroids, 2 with sodium cromoglycate (plain), and 5 with ACTH. 17 children had received aminophylline suppositories within four hours of admission. No significant difference 
Table Individual response to intramuscular salbutamol $(20 \mu \mathrm{g} / \mathrm{kg})$ and placebo injection administered under doubleblind crossover conditions

A. Patients treated with salbutamol after placebo

\begin{tabular}{|c|c|c|c|c|c|c|}
\hline Case no. & Age (years) & PEFR on admission & $\begin{array}{l}\text { Maximum PEFR } \\
\text { after placebo }\end{array}$ & $\begin{array}{l}\text { Rise in PEFR after } \\
\text { placebo }\end{array}$ & $\begin{array}{l}\text { Maximum PEFR } \\
\text { after salbutamol }\end{array}$ & $\begin{array}{l}\text { Rise in PEFR after } \\
\text { salbutamol }\end{array}$ \\
\hline $\begin{array}{r}1 \\
2 \\
3 \\
4 \\
5 \\
6 \\
7 \\
8 \\
9 \\
10\end{array}$ & $\begin{array}{r}15 \\
14 \\
14 \\
9 \\
7 \\
10 \\
14 \\
10 \\
16 \\
12\end{array}$ & $\begin{array}{r}36 \\
48 \\
74 \\
17 \\
11 \\
30 \\
8 \\
27 \\
22 \\
20\end{array}$ & $\begin{array}{r}53 \\
54 \\
90 \\
27 \\
14 \\
28 \\
9 \\
27 \\
26 \\
23\end{array}$ & $\begin{array}{r}17 \\
6 \\
16 \\
10 \\
3 \\
-2 \\
1 \\
0 \\
4 \\
3\end{array}$ & $\begin{array}{r}156 \\
112 \\
100 \\
48 \\
116 \\
53 \\
23 \\
43 \\
92 \\
91\end{array}$ & $\begin{array}{r}120 \\
64 \\
26 \\
31 \\
105 \\
23 \\
15 \\
16 \\
70 \\
71\end{array}$ \\
\hline
\end{tabular}

B. Patients treated with salbutamol before placebo

\begin{tabular}{|c|c|c|c|c|c|c|}
\hline Case no. & Age (years) & PEFR on admission & $\begin{array}{l}\text { Maximum PEFR } \\
\text { after salbutamol }\end{array}$ & $\begin{array}{l}\text { Rise in PEFR after } \\
\text { salbutamol }\end{array}$ & $\begin{array}{l}\text { Maximum PEFR } \\
\text { after placebo }\end{array}$ & $\begin{array}{l}\text { Rise in PEFR after } \\
\text { placebo }\end{array}$ \\
\hline $\begin{array}{l}11 \\
12 \\
13 \\
14 \\
15 \\
15 \\
16 \\
17 \\
18 \\
19 \\
20\end{array}$ & $\begin{array}{r}4 \\
10 \\
13 \\
4 \\
14 \\
11 \\
8 \\
8 \\
7 \\
4\end{array}$ & $\begin{array}{l}43 \\
50 \\
25 \\
12 \\
13 \\
39 \\
23 \\
48 \\
15 \\
\text { Could not use pneu }\end{array}$ & $\begin{array}{r}96 \\
56 \\
104 \\
37 \\
23 \\
94 \\
29 \\
119 \\
40 \\
\text { otachograph }\end{array}$ & $\begin{array}{r}53 \\
6 \\
79 \\
25 \\
10 \\
55 \\
6 \\
71 \\
25\end{array}$ & $\begin{array}{l}\text { Not given } \\
58 \\
\text { Not given } \\
\text { Not given } \\
23 \\
\text { Not given } \\
23 \\
\text { Not given } \\
30 \\
\text { Not given }\end{array}$ & $\begin{array}{r}10 \\
0 \\
15\end{array}$ \\
\hline
\end{tabular}

PEFR expressed as \% of predicted value for child's height.

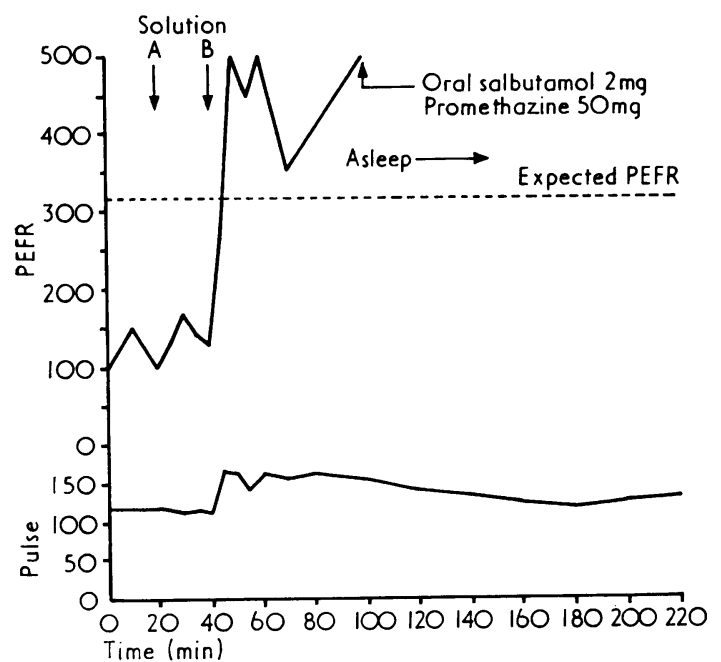

Fig. 1 Changes in PEFR (l/min) and pulse rates in one child after administration of solutions $A$ (placebo) and B (salbutamol).

between these groups and their response to treatment could be found.

The 5 children treated with open salbutamol $8 \mu \mathrm{g} /$ $\mathrm{kg}$ showed a mean pulse rise of $20 \pm 5$ beats per

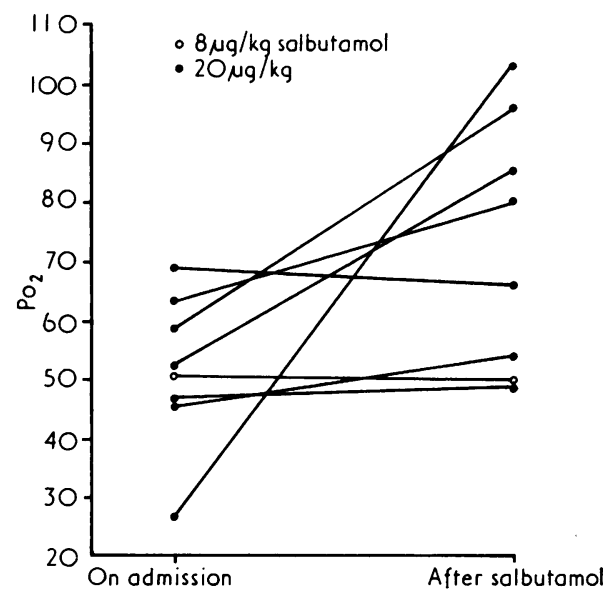

Fig. 2 Arterial $\mathrm{PO}_{2}$ levels $(\mathrm{mmHg})$ before and after administration of salbutamol in 8 children.

minute and those treated with open salbutamol $20 \mu \mathrm{g} / \mathrm{kg}$ (16 children) $21 \pm 6$ beats per minute. Those treated with salbutamol first in the blind trial showed a mean pulse rise of $22 \pm 4$ beats per minute and those with placebo first of $4 \pm 4(\mathrm{P}=$ $0.005)$. No arrhythmia was noted. The mean blood pressure for the whole group did not change nor 


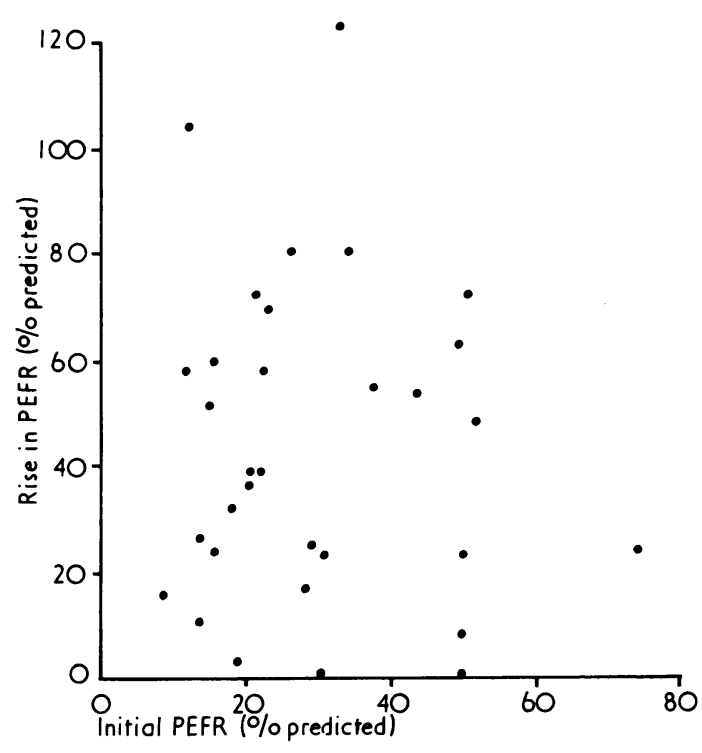

Fig. 3 Relationship between PEFR on admission and improvement after treatment with $20 \mu \mathrm{g} / \mathrm{kg}$ salbutamol.

was there a marked change in blood pressure in any child.

The only other side effect of salbutamol noted was tremor in 12 of the 36 children treated with $20 \mu \mathrm{g} / \mathrm{kg}$. In only 5 was it of a marked degree, and none of the children mentioned it. No quantitation of the tremor was attempted and observations were made on the outstretched fingers of the children. Where tremor was said to be marked it was noticed to interfere with manipulations such as holding a glass of water. The pain experienced at the site of the injection was short lived and no greater than to be expected from the trauma of any injection given to a child.

The 2 children who showed only a moderate response to the salbutamol in the double-blind trial and who were given a second injection of open salbutamol $20 \mu \mathrm{g} / \mathrm{kg} 60$ minutes after starting the trial (in one, 30 minutes after salbutamol and the other, 30 minutes after placebo) continued slowly to improve after the second injection. Steady clinical progress was noted with PEFR continuing to rise but without the rapid marked response reported in some of the other children to their first active injection. In one of these the pulse rate rose 12 beats per minute after the second injection but not after the first, and in the other no significant pulse rise occurred after either injection. No change in pulse rhythm or blood pressure occurred after the second injection and a mild tremor was noted in one of the children only after the second injection.

\section{Discussion}

Our results gave evidence that intramuscular salbutamol is an effective tool in the treatment of acute severe bronchospasm. A dose of $20 \mu \mathrm{g} / \mathrm{kg}$ produced a rapid response in 21 of the 36 children and no further acute treatment was necessary.

We have no parallel group treated with subcutaneous adrenaline with which to compare these results but we think that the salbutamol would compare favourably. Moreover, the specific $\beta_{2}$-adrenergic effect of salbutamol reduces its cardiotoxic potential as compared with adrenaline, though salbutamol did produce tachycardia in many children, albeit without arrhythmia or change in blood pressure. Potential cardiotoxic effects have also been ascribed to aminophylline (Lancet, 1973) and this danger is greater when the patient is hypoxic, as are many asthmatic children, so that salbutamol seems to be preferable.

We cannot explain why so many children who had previously received oral $\beta_{2}$-adrenergic agonists responded so well to intramuscular medication, and could not isolate any group of patients who could be designated probable responders before treatment. However, the rapidity of response to treatment (within 5 minutes of the injection) and the relatively painless nature of the injection, plus the low incidence of toxic effects (tachycardia and occasional tremor only) make intramuscular salbutamol a possible first line of treatment in all children suffering an acute exacerbation of asthma. It would also make it a possible domiciliary method of treatment in general practice.

We did not attempt to determine the duration of action of this form of treatment as we were only studying the potential of intramuscular salbutamol for inducing a remission in the asthmatic attack. We have, however, found it safe and effective to treat all children who have responded to intramuscular salbutamol with oral bronchodilators given 60 minutes or more after the administration of the salbutamol, and those children who have failed to respond to the intramuscular salbutamol with steroids and/or aminophylline (rectally or intravenously), given 30 minutes or more after the salbutamol.

\section{References}

Fitchett, D. H., McNichol, M. W., and Riordan, J. F. (1975). Intravenous salbutamol in management of status asthmaticus. British Medical Journal, 1, 53-55.

Lancet (1973). Intravenous aminophylline, 2, 950.

Riding, W. D., Dinda, P., and Chatterjee, S. S. (1970). The bronchodilator and cardiac effect of five pressure-packed aerosols in asthma. British Journal of Diseases of the Chest, $64,37-45$.

Correspondence to Dr. P. Thompson, Department of Paediatrics, Whittington Hospital London N19. 